Article

\title{
Zen in Distress: Theorizing Gender Dysphoria and Traumatic Remembrance within Sōtō Zen Meditation
}

\section{Ray Buckner}

Department of Religious Studies, Northwestern University, Crowe Hall, 1860 Campus Drive, Evanston, IL 60208, USA; raybuckner@u.northwestern.edu

Received: 14 September 2020; Accepted: 30 October 2020; Published: 4 November 2020

check for updates

\begin{abstract}
Gender dysphoria is considered a pronounced experience of distress in the bodies and minds of some transgender people. Examining the text Zen Mind, Beginners Mind by Shunryū Suzuki, I analyze some of the difficulties that may arise for transgender practitioners experiencing acutely strong gender dysphoria within the Sōtō Zen meditation experience. I seek to understand how physical and psychological gender distress may make concentration, and thereby realization, challenging and potentially harmful within a context of Sōtō Zen meditation. I consider how meditation can exacerbate the panic and traumatic remembrance of the body and mind, leading both to embodied struggles, as well as undoubtedly philosophical ones too. This paper theorizes gender dysphoria to exist beyond a state of unitary "distress" to include trauma. I put forward an understanding of gender dysphoria that is grounded in traumatic, gendered remembrances-what I call "sustained traumas." Within the meditation experience, I argue trans, gender dysphoric people may experience heightened disconnect, separation, and deepening into their solid and suffering "self" rather than open to the fundamental nature of emptiness, non-duality, and an empty and move-able core. Ultimately, I argue meditation may lead to a deepening of traumatic remembrance, posing potential corporeal and philosophical problematics for gender dysphoric practitioners within Sōtō Zen meditation.
\end{abstract}

Keywords: American Buddhism; gender dysphoria; trauma; Suzuki Roshi; Sōtō Zen; gender and sexuality; transgender; meditation; shenpa

\section{Introduction}

The teachings of the Sōtō Zen tradition are said to provide opportunities for experiencing the intimacy and immediacy of life. The simple teachings of Sōtō Zen include the complex and all-pervading concepts inherent to Mahāyāna Buddhism, including non-dualism, emptiness, absolute nothingness, and ordinary mind. Shunryū Suzuki Roshi (1975) puts forward the model of "just sitting." In sitting, there is an experience of sitting. One sits in order to sit. But one sits too to cultivate an open and unobstructed mind. With this clear mind, one is said to be able to see into the schisms present in ordinary life. One is said to be able to recognize the interconnectedness and emptiness of all phenomena. One can then achieve self-realization and potentially, through realizing this empty and open mind, help others along this path of liberation (Ueda et al. 1982).

While the path of Sōtō Zen is said to afford philosophical and embodied possibilities for many practitioners, this paper ponders if the forms of realization assumed in Sōtō Zen meditation are possible for the gender dysphoric frame. In the text I discuss below, I find the continuance of a calm body as a condition of practice and generation of a calm mind as a goal of practice appear central to the object of realization. Since gender dysphoria is marked by a pronounced experience of distress and discomfort in the bodies and minds of some transgender people (Mayo Clinic Staff 2019), I ask how the teachings of Sōtō Zen may run contrary to or in opposition with gender dysphoric experiences. I specifically use Suzuki Roshi's writing from Zen Mind, Beginner's Mind (1975) to think through gender dysphoria and 
Sōtō Zen's emphasis on "just sitting." In writing this piece, I draw in part from my own subjective experiences within different forms of meditation in the United States.

To start, what are the objects, and non-objects, of this study? First, this study is not about the positive uses of meditation for transgender practitioners. Several scientific studies have looked into the use of mindfulness and meditation to help with experiences of trauma (Follette et al. 2006), anxiety (Beauchemin et al. 2008), depression (Ramel et al. 2004), and stress (Astin 1997). To be clear, the goal of my inquiries is not exactly to understand whether meditation and the physical benefits of meditation are possible for the gender dysphoric frame. Instead, I am interested in understanding how sustained distress, as embodied by some gender dysphoric people, may make concentration, and thereby realization, difficult and potentially harmful within a context of Sōtō Zen meditation. Simply, the goal of this paper is to outline some of the challenges that may arise for transgender practitioners who are experiencing acutely strong gender dysphoria within the Sōtō Zen meditation experience and to consider how meditation can exacerbate the panic and traumatic remembrance of the body and mind, leading both to embodied struggles, as well as undoubtedly philosophical ones too.

This paper is concerned with understanding gender dysphoric experiences within the context of Sōtō Zen meditation. While this paper might illicit questions of comparison-that is, "might cisgender people also experience some of the discomfort outlined in your analysis?"-I am less concerned with questions of comparison here. I am concerned with the matter of gender dysphoria and issues that may arise for transgender, gender dysphoric practitioners within the context of Sōtō Zen meditation. My focus is thus solely on gender dysphoria and not on making claims of comparison between trans, gender dysphoric practitioners on the one hand, and cisgender practitioners on the other. Without doubt, these communities are in a relationship with each other. Trans, gender dysphoric bodies are always already in negotiation with a larger cisgender and hegemonic socio-political context. While I account for relationality and socialization in the sections below, I am committed to conceptualizing gender dysphoric experiences in particular.

I focus on Suzuki Roshi's Zen Mind, Beginner's Mind because Suzuki Roshi's emphasis on "just sitting" captures many of the material and philosophical commitments practiced within American Buddhist convert meditation communities. While I use Suzuki Roshi's text to think through gender dysphoria, I also believe Shamatha meditation-based practices, with their often single-pointed focus on the breath, could inspire similar embodied and philosophical struggles for trans, gender dysphoric practitioners. If Zazen and Shamatha meditations are largely focused on the act of sitting and breathing, then transgender, gender dysphoric experiences provide an opening to think through how that breath, body, and sit might be labored and challenged within the meditation experience. In this context, I do not believe that struggles surrounding gender dysphoria in meditation are necessarily unique to Sōtō Zen, but because I am using Suzuki Roshi's text and practices as the basis of my analysis, I try to limit my assertions to gender dysphoria within the Sōtō Zen meditation context. Analyzing the confluence of Buddhist philosophies alongside the embodied experience of sitting in Sōtō Zen Meditation offers an important and apt point of analysis for thinking through the relationship between gender dysphoria, trauma, and the body.

I begin with a literature review on transgender mental health, exemplifying some of the struggles transgender youth and adults face in contemporary American society. Next, I aim to theorize "dysphoria" and its interconnectedness with trauma, drawing from psychological literatures that outline meditation-based difficulties for practitioners with histories of trauma. I also place my scholarship within broader literature on studies of queer Buddhism. Next, I analyze the work of Shunryū Suzuki Roshi (1975) and consider how Buddhist concepts like "non-dualism" and "emptiness" intersect with transgender, gender dysphoric experiences. I ultimately argue that Sōtō Zen meditation may exacerbate gender dysphoria, re-awakening past experiences of subjugation and reinforcing harmful, and non-empty, notions of self. 


\section{Gender Dysphoria and Mental Health}

Throughout this paper, you will see both the terms "transgender" and "gender dysphoria." While always including the term "transgender," this paper takes up "gender dysphoria" as a category of analysis rather than the broader category of "transgender experiences." What is the difference? First, while trans may speak to a political and non-identitarian position similar to the operation of "queer," trans mostly encompasses a person's sense of identity or self. Dysphoria, on the other hand, is less about identity and more about a felt sense of experience and discomfort within the body. It is this embodied trauma and distress that I aim to theorize here.

While I will complicate and challenge the normative definition of "gender dysphoria" in the next section, I begin here with a brief and broad overview of the meaning of the term. Gender Dysphoria, the DSM-5 diagnosis, has a long and complicated history. Gender Dysphoria's previous diagnosis was Gender Identity Disorder, a diagnosis which came under intense critique from trans-affirming organizations for the ways that it pathologized transgender and gender-variant people (Lev 2005). Rather than an identity grounded in disability, Gender Dysphoria is instead "intended to be more descriptive," focusing on "one's discomfort as the problem, rather than identity" (Mayo Clinic Staff 2019). According to the Mayo Clinic Staff (2019), "Gender dysphoria is the feeling of discomfort or distress that might occur in people whose gender identity differs from their sex assigned at birth or sex-related physical characteristics. Transgender and gender-nonconforming people might experience gender dysphoria at some point in their lives. But not everyone is affected" (Mayo Clinic Staff 2019). While it is unclear how exactly to conceptualize gender dysphoria—as either an experience of the body, mind, or both -it is clear that gender dysphoria is a serious and often painful experience. As the Mayo Clinic goes on to explain, "Gender dysphoria can impair many aspects of life. Preoccupation with being of another gender than the one assigned often interferes with daily activities ... Anxiety, depression, self-harm, eating disorders, substance abuse and other problems can occur." 1

It is essential to hold discussions of gender dysphoric experiences within a larger psycho-social context. Transgender practitioners already enter meditation spaces facing significant social and psychological barriers. Transgender people suffer from heightened discrimination and victimization, as well as rejection from family and community members (Bouman et al. 2017). Many transgender people suffer from low self-esteem (Bouman et al. 2017) and a "high prevalence rates of mental health problems, particularly anxiety disorders and depression" (Bouman et al. 2017, p. 17). According to a study conducted by Bouman et al. (2017), transgender people had an "almost threefold increased risk of probable anxiety disorder," with $71 \%$ of trans men having a probable anxiety disorder. They found that for trans people, high levels of anxiety were particularly prevalent prior to medical or surgical treatment (Bouman et al. 2017, p. 22). Connolly et al. (2016) express how "studies since 2011 have shown that transgender youth have higher rates of depression, suicidality and self-harm, and eating disorders when compared with their peers" (Connolly et al. 2016, p. 489). Depression in transgender youth is significantly higher than their non-transgender peers (Connolly et al. 2016).

Self-harm is common in transgender communities. In a study analyzing self-harm and suicidality for gender dysphoric youth, Aitken et al. (2016) found that gender dysphoric children were 5.1 times more likely than non-gender dysphoric children to talk about suicide and 8.6 times more likely to self-harm or attempt suicide (Aitken et al. 2016). They found that children with "gender dysphoria show an increased rate of self-harm/suicidality as they get older" (Aitken et al. 2016, p. 513). In a report by Clark et al. (2014), transgender students had higher rates of attempted suicide in the past 12 months when compared to cisgender students, with $19.8 \%$ of transgender students attempting suicide vs. $4.1 \%$ of cisgender students. Transgender students also had higher rates of self-harm, with $45.5 \%$ of trans students self-harming vs. $23.4 \%$ of cisgender students (Connolly et al. 2016).

1 When I speak of gender dysphoria in this paper, I am most often referring to the embodied experience of distress (lowercase gd) and not the formal DSM-V Gender Dysphoria medical diagnosis (capital GD). 
Aitken et al. (2016) explain that while there may be various components that inform the confluence of gender dysphoria with suicidal ideation and self-harm, "One possibility is that gender dysphoria is inherently distressing, which leads to self-harm or suicidal thoughts and behaviors" (Aitken et al. 2016, p. 514). They go on to state, "The most common explanation in the extant literature is that suicidality is caused by social ostracism or lack of social support" (Aitken et al. 2016, p. 514).

Stigma is central to understanding mental health struggles faced by transgender people. Walter Bockting (2014) writes that "in a national study of the US transgender population, 70\% reported verbal abuse and harassment related to being transgender and 38\% reported employment discrimination" (Bockting 2014, p. 323). Depression and stigma are often interconnected, with depression "associated with transgender-related stigma and discrimination" (Bockting 2014, pp. 323-24). Bockting explains that "Children who are visibly gender role nonconforming in childhood have no choice but to learn to cope with the attached enacted stigma at an early age. Their coming-out process is accelerated. Stigma and rejection at an early age put these gender-nonconforming youth at risk for isolation, academic performance issues and school dropout, homelessness, substance abuse, and suicide" (Bockting 2014, p. 324). Bockting connects the experience transgender people are subjected to with the minority stress model, which "postulates that stigma attached to one's minority status creates added stress beyond general stress that individuals from both the majority and minority populations face" (Bockting 2014, p. 323). Ultimately, social stigma is central to the stress, depression, and suicidality that transgender youths and adults experience (Bockting 2014).

What is the purpose of addressing transgender mental health in a paper focused on gender dysphoria and Zen meditation? Though not all transgender people experience gender dysphoria, transgender people more broadly are subject to conditions of existence which include stigma, discrimination, and heightened anxiety and depression. When transgender people enter meditation spaces, then, we must be aware of the significant socio-psycho-cultural weight they carry. Gender dysphoria must be held within this larger container of trans exclusion and ostracization.

\section{Re-Conceptualizing "Dysphoria" and Its Relationship to Trauma}

Before examining the confluence of Sōtō Zen meditation and gender dysphoria, it is crucial to re-conceptualize gender dysphoria. We must broaden this conceptualization if we are to offer a more inclusive and intricate reading of gender dysphoric experiences within Sōtō Zen meditation. In particular, we must broaden this conceptualization if we are to consider how trauma and gender dysphoria exist within the meditation experience.

Though dysphoria within a "gender dysphoria" context is often labeled in a unilateral way as only "distress," distress is more dynamic than unidimensional. Dr. Danielle Fetty defines distress as "self-reported emotional upset that includes feelings of general distress, anxiety, anger, and depression" (Fetty 2016, p. 11). The American Psychological Association defines "distress" as "a negative emotional state in which the specific quality of the emotion is unspecified or unidentifiable" and as a "negative stress response, often involving negative affect and physiological reactivity: a type of stress that results from being overwhelmed by demands, losses, or perceived threats" (APA-American Psychological Association 2020a). In this way, distress may not be altogether separate from the terrain of mental health but may draw on some of the psycho-socio-cultural strings which inform the creation of this endured stress.

I seek to conceptualize dysphoria as beyond a unitary state of distress to include prolonged and complex traumas. Giovanardi et al. (2018) theorize "complex trauma" as integral to gender dysphoric experiences. Rather than drawing from a PTSD diagnosis that tends to rely on a singular moment of trauma, Giovanardi et al. (2018) conceptualize gender dysphoria through Courtois' notion of "complex trauma," which in addition to PTSD, includes "child maltreatment, neglect, domestic violence and other attachment-related trauma" (Bailey et al. 2007). Giovanardi et al. (2018) explain that "Complex trauma can be understood as a set of experiences of cumulative, chronic and prolonged traumatic events, most often of an interpersonal nature, involving primary caregivers and frequently 
arising in early childhood or adolescence" (Giovanardi et al. 2018, p. 13). Julian Ford (2017) explains that "CPTSD is controversial, and as its name indicates, clinically complex, which is understandable given the severity of betrayal, violence, and existential threat and harm that catastrophic traumatic stressors can cause to individuals and entire societies" (Ford 2017, p. 281). While Giovanardi et al. (2018) consider trauma to be a dimension independent from Gender Dysphoria (the medical diagnosis), in this paper I theorize gender dysphoria as a form of "sustained trauma."

The American Psychological Association defines trauma as "any disturbing experience that results in significant fear, helplessness, dissociation, confusion, or other disruptive feelings intense enough to have a long-lasting negative effect on a person's attitudes, behavior, and other aspects of functioning. Traumatic events include those caused by human behavior (e.g., rape, war, industrial accidents) as well as by nature (e.g., earthquakes) and often challenge an individual's view of the world as a just, safe, and predictable place" (APA—American Psychological Association 2020b).

Gender dysphoria should be conceptualized as a trauma because of the enduring fear, helplessness, and intense disruption of feelings felt within many trans, gender dysphoric bodies and minds. Stephen Cope writes that "Sometimes we encounter experiences that so violate our sense of safety, order, predictability, and right, that we feel utterly overwhelmed-unable to integrate, and simply unable to go on as before. Unable to bear reality. We have come to call these shattering experiences trauma" (Treleaven 2018, p. 3). Borrowing from these insights, I understand moments of trans remembrance, encapsulated by experiences of shame, rejection, and complete shock and overwhelm, to be a form of intra-personal and social trauma. These moments of trans breakage-moments in which a person's sense of self is ruptured by a challenged and rejected view-are enduring embodied experiences contained within many trans bodies and minds. These experiences of "long-lasting negative effect[s]" (APA-American Psychological Association 2020b) happen not once but throughout a person's embodied life. Gender dysphoria, rather than only "interpersonal," which is characteristic of "complex trauma" (Giovanardi et al. 2018), is often held within a simultaneously larger structure of trans stigmatization, rejection, neglect, and discrimination (Bockting 2014). Trans bodies and minds hold a multitude of stresses built from both disturbing significant events and a cumulative, enduring transphobic socio-cultural context, creating a lasting and sustained trauma to trans bodies and minds.

What do I mean when I refer to the gender dysphoric "body" and "mind"? When I speak of the "gender dysphoric body," I refer both to the physical body and the thought of the physical body. For example, the gender dysphoric body within meditation may experience heightened anxiety, or may experience more difficulty breathing as a result of wearing a chest binder. This is a physical example of how gender dysphoria within meditation may affect the body. But the thought of the body is equally important. While thoughts would seem to signify the terrain of "mind," the mind is dwelling on a body as it is-perhaps, a body with or without breasts, or a body with or without hair, or a body in some way different than how that practitioner yearns the body to be. I count the thought of the body to be the terrain of the body, inseparable then from the terrain of mind. The terrain of "mind," then, a mind which I often refer to as the "psychological" dimension of gender dysphoria, concerns the anguish and cyclic thoughts that arise for trans, gender dysphoric practitioners within the meditation experience. The terrain of mind is mostly where shame, panic, and traumatic remembrance exist. Yet, these sensations belong likely both to the terrain of mind and body. Where the mind is anguished, the body will likely feel that pain and panic as well. So the body and mind are often inseparable, mutually affecting and in relationship to one's physical and psychical experience.

My theorization of "trauma" draws from the work of Dr. David Treleaven, whose book Trauma-Sensitive Mindfulness: Practices for Safe and Transformative Healing (2018), addresses the potential dangers and limitations of mindfulness meditation for those experiencing trauma. Treleaven describes trauma as "incapacitating" (Treleaven 2018, p. 22). Though Treleaven addresses mindfulness meditation, he argues that meditation, which is an act that draws us closer into sustained remembrances, has the potential to re-traumatize survivors. He explains that paying "Direct, sustained contact with traumatic stimuli-without adequate preparation-locks survivors into a potentially debilitating loop" 
(Treleaven 2018, p. 42). Because mindfulness meditation calls on practitioners to pay close attention to their internal experiences, the remembrances of trauma, memory, and scent can intensify within meditation, yanking practitioners into a "vortex of trauma" (Treleaven 2018, p. 41).

A burgeoning area of research focuses on exactly this question of under-reported and understudied experiences in meditation, "experiences that are described as challenging, difficult, distressing, functionally impairing, and/or requiring additional support" (Lindahl et al. 2017, p. 1). In a study by Lomas et al., "Meditators reported 'exacerbation of psychological problems,' including anxiety and depression, 'troubling experiences of self,' and 'reality being challenged,' which included out-of-body experiences and in one case resulted in patient hospitalization for psychosis" (Lindahl et al. 2017, p. 5). Intentionally inquiring into difficult and distressing meditation-based experiences in practitioner-meditators, Lindahl et al. found that "the associated level of distress and functional impairment ranged from minimal and transient to severe and enduring" (Lindahl et al. 2017, p. 1). Central to the study at hand, Lindahl et al. found meditation to inspire "affective changes" in the experiences of meditators. Fear and anxiety were prominent, with $82 \%$ of surveyed practitioners reporting affective changes, including "fear, anxiety, panic or paranoia" (Lindahl et al. 2017, p. 18).

While Lindahl et al.'s study acknowledges positive affective experiences within meditation, they also find that periods of bliss are soon followed by depression and even suicidal ideation (Lindahl et al. 2017). This finding aligns with Dr. Willoughby Britton (2019) who argues that meditation may reach a certain inflection point where instead of traveling upwards towards positive effects, it returns back down to create "undesirable effects" (Britton 2019, p. 159). She argues the "relationship between meditation amount and well-being shows signs of non-monotonicity, or a combination of positive, null and negative effects" (Britton 2019, p. 161). While there is an optimal zone of experiencing "mindfulness-related processes," there are also processes that can cause negative effects, including "increased arousal and emotional intensity, depression, sadness, anxiety, panic, traumatic flashbacks, and clinical pain syndromes ... and all of these effects have been reported in the context of mindfulness meditation training" (Britton 2019, p. 160).

Researchers investigating negative or distressing experiences with meditation turn to the question of trauma directly. They find that for practitioners with a history of trauma, "it was not uncommon for them to report a re-experiencing of traumatic memories, and even practitioners without a trauma history similarly reported an upwelling of emotionally-charged psychological material" (Lindahl et al. 2017, p. 19). In a study of Vajrayana Buddhist practitioners, Lindahl (2017) found that, for some, the experience of prostrations and visualizations "can result in the upwelling of strong emotional and psychological content" (Lindahl 2017, p. 12). He writes that practitioners with a history of trauma who "re-experienced their traumas in the context of practice reported being particularly distressed and impaired" (Lindahl 2017, p. 12).

Within a context of trauma, Treleaven discusses the significance of dis-integration. He argues that part of what occurs for trauma survivors is an inability to integrate traumatic memories and experiences into one's bodily and psychological operations. Not all traumas result in dis-integration or posttraumatic stress. But for those that do, a person's “Thoughts, memories, and emotions become cut off from our experience or continually flood our field of consciousness ... . Our bodies continue to respond with alarm even though people close to us may try to reassure us otherwise" (Treleaven 2018, p. 14). Trauma does not end but floods. In this experience of posttraumatic stress, "traumatic symptoms live on past the traumatic event" (Treleaven 2018, p. 11), the imprint of this moment following "us into the present, destined to replay itself over and over again." As Treleaven goes on to state, "Posttraumatic stress fundamentally challenges the notion that time can heal all wounds" (Treleaven 2018, p. 11). In this way, traumatic remembrance is not an end for a survivor but a continual process of re-opening, cyclic replaying, and dissociation. This process of re-opening to gender dysphoric traumas can be pronounced in meditation. Collectively, these literatures provide us a framework for conceptualizing gender dysphoria through a lens of trauma, traumatic remembrance, and embodied distress. 
Before moving forward, it is essential to situate my scholarship within another burgeoning field of research, specifically the study of queer Buddhism in contemporary society. While this paper solely focuses on gender dysphoric experiences, other scholars have paid attention to the ways that identity, marginalization, and queerness and transness function in studies of Buddhism. Gleig (2014) provides an ethnographic study of the East Bay Meditation Center in Oakland, CA. Gleig (2012) includes a further look into the operations and challenges to heteronormativity within this mostly convert Buddhist community and the ways intersections of identity around race, gender identity, sexuality, and disability function in that space. Scherer (2020) analyzes queer Buddhism through philological, historical, and cultural lenses, outlining what Scherer calls five parameters for a Queer Dharmology. Corless (2007) offers a queer dharmology of sex as it relates to lay Buddhism. Hu lastly describes a vision for "Buddhism and Sexual Orientation" by offering readings of fundamental Buddhist concepts in relationship to sexual and gender minorities (Hu 2017). Despite being just a sampling of scholarship on queer Buddhism, these above papers outline the diverse and important ways that scholars are engaging questions of queer sexuality, gender, and Buddhism.

I place my current study on gender dysphoria in community with theirs. Gleig's article (2014) helpfully demonstrates the location and context of my own research and some of the philosophical underpinnings that inform my study. Gleig places her study at the East Bay Meditation Center, where a "number of its core and visiting teachers have been primarily trained in the Sōtō tradition, particularly through the San Francisco Zen center ... Moreover, many of EBMC's practitioners have mainly encountered Buddhism through the work of popular Western Buddhists teachers such as Pema Chödrön, or Jack Kornfield, or Asian modernizers such as Thich Nhat Hanh and the Dalai Lama" (Gleig 2014, p. 315). While Gleig does not mention Suzuki Roshi by name, Suzuki Roshi is the founder of the San Francisco Zen Center. In this way, my scholarship draws on the influence of Suzuki Roshi within an American Buddhist context grounded in both Sōtō Zen influences as well as the confluence of other forms of Buddhist thought.

Second, Gleig (2014) addresses the ways that queer and gender-queer practitioners are able to realize fundamental aspects of their identity within meditation, connecting their relative existence as gender-queer to experiencing fundamental, absolute notions of emptiness and non-self. Gleig quotes a gender-queer practitioner in stating, "Being gender-queer is an experience of the non-essentialism of Buddhism - through my own changing experience of gender, I feel I understand the Buddhist notion that the self is fluid and conditional" (Gleig 2014, p. 318). Like Gleig's research, I am thinking through the ways relative experiences of transness coalesce with absolute experiences of emptiness, non-dualism, and transience. However, while Gleig's research highlights possibilities within the meditation experience for queer and trans practitioners, I underline some of the challenges that arise for trans, gender dysphoric existences. My research offers a unique contribution to literature on queer and transgender Buddhism by considering how gender dysphoria adds particular challenges to the experience of meditation for trans, gender dysphoric practitioners.

My research fits well into Scherer's model of queer dharmology, specifically the prongs "Conceptualization" and "Application." The first term is concerned with "the development, in dialogue with [Queer Theory], of a Constructive-Critical queer readings of Buddhist tenets (such as karma, no-self, emptiness)" (Scherer 2020, p. 20). Undoubtedly, this current piece aims to complicate notions of emptiness and non-dualism by providing a gender dysphoric reading and engagement with these Buddhist tenets. Second, my research aligns with the "Application" prong, which concerns "The adaptation of queer/trans* affirmative spaces and technologies of the (No-)Self in Buddhist practice including meditation" (Scherer 2020, p. 20). This project is strongly concerned with the ways that trans and gender dysphoric experiences inform philosophical and bodily offerings within American Buddhist spaces. By paying close attention to gender dysphoria within the context of Sōtō Zen meditation, my research enhances bodily, psychical, and philosophical understandings of trans, gender dysphoric experiences within meditation. Lastly, this research is unique in its analysis of the 
gender dysphoric mind and its co-constitutive struggle with the body, specifically the ways this gender dysphoric body and mind (re)experience trauma within meditation.

\section{Zen in Gender Distress}

I turn now to thinking through gender dysphoria in Sōtō Zen meditation. I seek, ultimately, to read the following Zen Buddhist texts through a lens attuned to the difficulties that may arise for trans, gender dysphoric persons. In Zen Mind, Beginner's Mind (1975), Suzuki Roshi outlines the connection between practice and realization. Suzuki Roshi illustrates that while practitioners are "just sitting" in meditation, they are learning to cultivate a pure and unbiased mind. Suzuki Roshi writes, "But it is when you sit in zazen that you will have the most pure, genuine experience of the empty state of mind. Actually, emptiness of mind is not even a state of mind, but the original essence of mind." He goes on to state, "'Essence of mind,' 'original mind,' 'original face,' 'Buddha nature,' 'emptiness' —all these words mean the absolute calmness of our mind. You know how to rest physically. You do not know how to rest mentally" (Suzuki 1975, pp. 128-29). In this articulation, sitting allows practitioners to experience oneness of mind and the emptiness of all phenomena.

There are several assumptions that underly Suzuki Roshi's expression of realizing emptiness within Sōtō Zen meditation. First, it is assumed that by sitting in Zazen, one will experience the original essence of their mind, which is a pure, genuine and "empty state of mind." Second, within this experience, it is assumed that all the phenomena listed above, including "original face" and "emptiness," will be embodied through the "absolute calmness of our mind" (Suzuki 1975, p. 129). Third, it is assumed that individuals "know how to rest physically." I draw attention to these operations because I am interested in the relationship between calmness as a condition and goal of practice and realization. How important is calmness of body and mind in the experience of realization? If calmness of mind is central to the object of realization, does a gender dysphoric practitioner who instead experiences panic face barriers to these forms of realization? Might panic also lead toward realization?

We need to take a close look at the operations of calmness vis-a-vis larger questions of realization. According to the teachings of Suzuki Roshi, while the body is said to know how to rest physically, the mind does not. The aim of meditation would thus be to experience that calmness of mind so that the mind, along with the already resting body, can experience the oneness of ordinary mind.

Suzuki Roshi argues that in order to have emptiness, we need a soft and natural mind. Naturalness and flexibility are thus essential to the path of realization. Suzuki Roshi puts it this way: "Whatever you do, this attitude is necessary. Sometimes we say nyu nan shin, 'soft or flexible mind.' Nyu is 'soft feeling'; nan is 'something which is not hard'; shin is 'mind.' Nyu nan shin means a smooth, natural mind. When you have that mind, you have the joy of life. When you lose it, you lose everything. You have nothing. Although you think you have something, you have nothing; But when all you do comes out of nothingness, then you have everything. Do you understand? That is what we mean by naturalness" (Suzuki 1975, p. 110).

In having softness, there is the ability for the mind to move. If one's mind cannot move, if the mind is too hard, one cannot realize these fundamental truths of realization. Naturalness and calmness of mind are thus central to sitting in Sōtō Zen meditation and connecting one's experience between small and large mind. The mind must be able to be pliable if it to connect with "the joy of life" and the "naturalness" of existence.

Without the calm experience of mind, the mind and body are divided. In this divided state, one cannot see clearly and abide fully in the nature of impermanence, non-dualism, and emptiness. As Suzuki Roshi articulates, "When we cross our legs like this, even though we have a right leg and a left leg, they have become one. The position expresses the oneness of duality: not two, and not one. This is the most important teaching: not two, and not one. Our body and mind are not two and not one" (Suzuki 1975, p. 25). One cannot abide in the fullness of mind and the fullness of experience if the left leg is conceptualized as fundamentally disconnected and separate from the right. The left 
does exist and the right does exist; they are two, and yet they are fundamentally one - part of the same interconnected fabric of existence.

In non-duality there is transience. In emptiness there is movement. In this time of meditation, the physical breath and one's mental thoughts all come and go and come again. As Suzuki Roshi articulates, "The basic teaching of Buddhism is the teaching of transiency, or change. That everything changes is the basic truth for each existence. No one can deny this truth, and all the teaching of Buddhism is condensed within it" (Suzuki 1975, p. 102). Ultimately, Suzuki Roshi argues transience is at the core of all Buddhist teachings, for transience represents the realization of emptiness: phenomena and experiences are fundamentally impermanent. Suzuki Roshi goes on to explain, "When we inhale, the air comes into the inner world. When we exhale, the air goes out to the outer world. The inner world is limitless, and the outer world is also limitless ... In this limitless world, our throat is like a swinging door. The air comes in and goes out like someone passing through a swinging door." He then writes, "If you think, 'I breathe,' the ' $\mathrm{I}$ ' is extra. There is no you to say 'I.' What we call ' $\mathrm{I}$ ' is just a swinging door which moves when we inhale and when we exhale. It just moves; that is all" (Suzuki 1975, p. 29). This sense of movement and flow is fundamental to the experience of meditation and the ability for the mind and body to interconnect with one's "personal" world and larger existence. One's own world is never just one's own but intricately tied and flowing with the existences of other sentient beings. This flow of air from in to out and out to in is both the act of breath and the embodiment of realization into the nature of impermanence and emptiness. There is no solid "I" to breathe, it is just a swinging door of breath, connecting to this empty "you" to the greater empty "world."

In turning to the subject of gender dysphoria, I would like to argue that each of these larger philosophical phenomena may exist in partial conflict with gender dysphoric experiences. Let us pay particular attention to this metaphor of a "swinging door." If non-duality and emptiness represent the ability for the mind to move and exist in transience, realizing its fundamental nature within a moveable and impermanent existence, then this may pose problems for the practitioner whose mind and body are fundamentally stuck. In turning to the topic of gender dysphoria in Sōtō Zen meditation, per Suzuki Roshi's above philosophies, I would like to argue that not only is there significant conflict with the dysphoric person experiencing and generating calmness of mind, but also that the assumed experience of the "rest[ing] body" (Suzuki 1975, pp. 128-29) must be fundamentally questioned. In thinking through the trans, gender dysphoric body, we are imagining a body that is, in part, at war with itself. We are imagining a body that longs to embody something different than it currently does. We are imagining a body suffering from the distress of its corporeal and psychic state-a body torn between genders or ideas of what that body should, or can, be. We are also positioning a body that may be subject already to heightened anxiety, depression, and suicidal ideation born, in part, from societal stigma, as discussed in the earlier literature. While these struggles of body may indeed be largely marked in the psychic war of the mind, I argue in the case of gender dysphoria that the body and mind are co-constitutive; a person cannot separate one from the other. That is, within the experience of gender dysphoria, the body and mind are intricately intertwined. While the struggle and war may be largely located in the mind, it is inseparable from the materiality of the body-what the body was, what the body currently is, and what the body may be.

I argue that gender dysphoria is marked by a sustained multi-temporal experience and chronic trauma, a distress that marks the body and mind in moments beyond one. The Tibetan Buddhist concept, shenpa, can be an exceptionally useful tool for framing and thinking through gender dysphoric experiences of body and mind within Sōtō Zen meditation. While this paper focuses on Sōtō Zen meditation, I believe it is worthwhile to think with this important term. Because shenpa captures a specific form of psychical, cyclic mental anguish, it best captures the potential harm faced by transgender practitioners experiencing acute gender dysphoric and traumatic remembrance within the meditation experience.

I understand gender dysphoria in Sōtō Zen meditation to be, at times, an illustration and embodiment of shenpa. Shenpa is a Tibetan Buddhist term that captures a sense of "getting hooked." 
Pema Chödrön characterizes shenpa as a touch, smell, or comment that takes a person out of the present moment and into a spiral of panic, anxiety, and fear. It is from Chödrön's writings, particularly her book, Practicing Peace in Times of War (Chödrön 2006), that I consider how shenpa might be a useful concept for understanding the suffering experienced by gender dysphoric people in meditation. Shenpa can be strongly present in the experience of meditation for gender dysphoric people, for shenpa can function like an ever-tightening cycle of bodily and psychical distress. Once one thought flows, the mind can quickly become obscured and burdened by related and heightened inadequacies. For example, when the breath is unable to breathe while wearing a trans-affirming chest binder, this may lead to the mind feeling unable to cope with its inadequacies, which may lead to remembering that one is a failed being. One's body remembers a pained moment of mis-treatment, which reminds them that their body has so often been met with generalized laughter and abjection, which leads them to believe, and understand a truth, that their body and being are fundamentally wrong. Shenpa in this way can exist as the deepening obscurity and hookedness of the mind and body into a state of extreme gender distress. If transgender, gender dysphoric practitioners are already subject to heightened stigma and discrimination (Bockting 2014, pp. 323-24) in tandem with heightened bodily depression (Connolly et al. 2016) and anxiety (Bouman et al. 2017), this could more deeply exacerbate the pull of the body and mind into distress within the meditation experience. I thus understand gender dysphoria within meditation as the tightening into an intense and distressed body and mind, a mind that is reminded again and again of its traumatic past and perhaps failed embodied future.

In drawing on shenpa and dysphoria, I am attempting to speak to an inherently distressed and schismed internal experience. If Sōtō Zen meditation is an experience that welcomes an opening - an opening to breath, an opening to the coming and going of thoughts, and the realization of impermanence-it is an opening that one cannot dictate. If meditation is an opening to the body, one cannot predict what that body will remember. If meditation is an opening to the mind, one cannot predict the trouble, pain, or traumatic remembrances that may soon follow. In many ways, a moment of dysphoria is a moment of stuck-ness. It is a moment, for some, of being trapped in what one sees and who one is. One essentially feels pinned down and suffocated by their embodied experience.

Rather than stuck-ness presenting an opportunity to look clearly into suffering and cultivate wisdom, this stuck-ness can cause a person to deepen into their suffering, become trapped by it. In this position, the breath becomes shallow and cornered. The person becomes less interconnected with the world around them, and more suffocated by the body in which they abide. Rather than an existence that allows for calmness of body as a condition of the practice, one exists in panic and distress. Rather than the breath flowing in and out, it is labored and caught. Where anxiety and depression are strong, or the presence of suicidal ideation is present too, this stuck-ness and gripped-ness could strikingly and perhaps dangerously panic and distress the trans practitioner within the act of meditation. Thus, instead of meditation existing as a means of realization into these forms of suffering, it can place deepened attention onto sites of suffering and traumatization. This internal experience then poses not only philosophical problematics toward realizing non-dualism and transience but embodied ones too.

These questions of embodied pain and the difficulties of realizing transience return us to the topic of trauma within meditation. Treleaven writes, "When we ask someone with trauma to pay close, sustained attention to their internal world, we invite them into contact with traumatic stimuli-thoughts, images, memories, and physical sensations that may relate to a traumatic event. As my friend experienced, this can aggravate and intensify symptoms of traumatic stress, in some cases even lead to retraumatization-a relapse into an intensely traumatized state" (Treleaven 2018, p. 6) Here gender dysphoria can become heightened in meditation, such that the mind becomes hyper-focused on its bodily and psychical remembrances, the mind becomes tightened in its suffocation of a solid and inescapable self and body, and the mind is potentially unable to open to an unobscured and transient reality. Again, we present here philosophical and material challenges, the latter of a clearly painful and burdened nature. 
Related to the philosophical dimension of this work, part of what I am raising here is that a gender dysphoric person whose body and mind are at war with themselves and their greater oppressive society may have difficulties experiencing the Buddhist concepts put forward by Suzuki Roshi, specifically emptiness, non-dualism, and ordinary mind. Perhaps more strikingly, trans people with gender dysphoria may experience heightened distress through this process of meditation, felt as a more heightened dualistic and incomplete sense of self. If, in meditation, the body and mind feel fundamentally like "two," such that it is existing between separate and torn spheres/genders, and entirely not like "one," such that the body feels fundamentally incomplete, uncomfortable, and unsafe, can the gender dysphoric person achieve this realization of non-dualism in Sōtō Zen meditation? This sense of being fundamentally at war between a solid and stuck body and mind presents challenges to this "most important teaching: not two, and not one. Our body and mind are not two and not one (Suzuki 1975, p. 25)."

Not only can the mind become hyper-focused on remembrance, but notions of a "self," including a wrong and long-denied "self," may become painfully evident. Here, I'd like to think with another Buddhist psychological term known as "the trance of unworthiness." In her book Radical Acceptance: Embracing Your Life with the Heart of a Buddha (2003), Dr. Tara Brach theorizes desire, shame, and the feeling of moving through the world as though "not enough." Brach introduces her reader to the concept "the trance of unworthiness." In this trance, Brach argues one feels as though they are lacking, insignificant, stuck, and unworthy of love and belonging. Brach articulates how this trance can be experienced in myriad ways, but one ultimately operates from an underlying "knowledge" they are flawed. This sense of being fundamentally flawed permeates a person's life.

Brach explains how much of a person's present pains, reactions, and "trances of unworthiness" stem from childhood; notably, a continued reception of "no" in the face of one's desires and needs. She writes,

Our sense of self emerges from the ground level of all experience-our reactivity to intense pleasant or unpleasant sensations. When we want loving attention ... we are feeling certain sensations in our body-perhaps the aching of longing around the heart, as well as excitement and openness. When the answer to our need and desire is no, the physical sensations of contraction we experience are intense. We feel shame-the desire to hide-and the danger of fear. When we experience this wanting and not getting over and over, we make an enduring association: Our wanting leads to fear and shame. This intense cluster of reactive feelings, locked in the body, forms the energetic core of a wanting self. (Brach 2003, p. 135)

One's "self" is constructed around a person's desires and their impossibilities. One's desires—one's yearning, wishes, wanting, call—are formative to the development of one's identities. Though not addressed in Brach's book, I argue these nodes of desire are particularly significant when entering the realm of transness. In this way, the "no" a trans person experiences may not be a generalized "no" but one tender to the context of the body at hand. For the trans person, what was once a "no," a rejection of violence to which one faced subjection, has heavy and upsetting implications, for the body remembers that moment of "no"- that moment one's personhood, ability to live free (in peace and from violence), was foreclosed. In turn, in the present or future, one is foreclosed by that past (and yet present) trauma and remembrance. One is panicked, closed down, and fearful. One's world is temporarily ended now, even for a brief moment, because of a world shamed or un-allowed long ago. The trans frame thus embodies particular waves of fear and shame in the face of "no"s, specifically "no"s surrounding a trans person's body, desire, and worth.

While people who do not experience gender dysphoria also struggle with shenpa and this "trance of unworthiness" (of course, neither Brach nor Chödrön's texts are aiming to specifically capture transgender experiences), I believe there is something substantial about the experience of distress that may arise in Sōtō Zen meditation for transgender, gender dysphoric practitioners. The fact that Sōtō Zen meditation may open transgender, gender dysphoric practitioners to increased remembrance of 
trauma and sustained psychical distress is something we must as scholars pay attention to and seek to understand with clarity and precision.

I am arguing there is a co-constitutive trauma of body and mind within meditation for gender dysphoric practitioners. Within a gender dysphoric meditation experience, then, the body can dissociate and exacerbate traumatic memories of its gendered past, challenged gendered present, and perhaps anxious and fearful embodied future. Within meditation, the gender dysphoric person's mind cannot escape. The mind is gripped. The mind is triggered. The mind is aware of what it is not (worthy) and what it is (a failed gender). The mind is aware of what it is not (the gender they see themself as) and what it is (a failed child). The mind remembers what it is not (supported) and what it is (never belonging). For some, meditation may be a space of coming undone, meaning one's solid sense of self, empty awareness of existence, and empty mind and transient self, are all possibilities within a normative meditation experience. I am suggesting that meditation and "just sitting" can be challenged experiences within a gender dysphoric body in which the body is opening to a world of unending remembrances-a mind and body full of sustained gendered traumas.

\section{Conclusions}

In concluding, I conceptualize this paper as more exploratory than argumentative, and do not mean to argue that the only way to conceptualize and experience gender dysphoria within Sōtō Zen meditation is through suffering and immovability. Instead, I simply wish to inquire how gender dysphoric individuals might experience Sōtō Zen meditation from an embodied standpoint and how this experience may have philosophical implications, including barriers to realizing emptiness and non-dualism. Future research must directly explore the vast embodied experiences of gender dysphoric people in meditation.

Suzuki Roshi writes that "'Step by step I stop the sound of the murmuring brook.' When you walk along the brook you will hear the water running. The sound is continuous, but you must be able to stop it if you want to stop it. This is freedom; this is renunciation. One after another you will have various thoughts in your mind, but if you want to stop your thinking you can. So when you are able to stop the sound of the murmuring brook, you will appreciate the feeling of your work. But as long as you have some fixed idea or are caught by some habitual way of doing things, you cannot appreciate things in their true sense" (Suzuki 1975, pp. 11-12).

In many ways, this paper is asking, "Can one stop the sound of the murmuring brook called dysphoria?" If the answer is "no," what are the implications for gender dysphoric people on the path of liberation? If the answer is "yes," how does the gender dysphoric practitioner accomplish this? Are there specific struggles and insights transgender dysphoric people navigate or is their path of realization like cisgender people and those of other embodied identities?

In my own readings, there is something about the distress of gender dysphoria that, at times, cannot be stopped and may even deepen during meditation. In this experience, the teachings of Sōtō Zen meditation and Mahữāyāna Buddhism, particularly ordinary mind, absolute nothingness, emptiness, and impermanence, become more difficult to cultivate. Trans, gender dysphoric people, according to my reading, might experience heightened disconnect, separation, and deepening into their solid and suffering "self" rather than open to the fundamental nature of emptiness, non-duality, and an empty and move-able core. Most importantly, meditation may open gender dysphoric people to heightened traumatic remembrances, not only obstructing Buddhist paths toward realization but potentially causing relative, embodied corporeal and psychological harm to transgender, gender dysphoric practitioners.

I am ultimately arguing that Sōtō Zen meditation, and likely other single-pint of focus or breath-focused meditations like shamatha meditation, can create significant psychical and bodily pain for gender dysphoric practitioners. Because of these potential psychical and bodily struggles within the experience of meditation, transgender, gender dysphoric practitioners may experience embodied suffering that can disrupt both the relative experience of meditation and absolute experiences of 
realizing non-dualism and ordinary mind. This topic of study fundamentally calls for many more questions than answers at this stage. Understanding gender dysphoric and transgender experiences within meditation is a necessary and exciting possibility, both for comprehending philosophical questions related to trans Buddhist experiences but also for apprehending all that the body carries, both within and outside the Buddhist meditation space. I would like to end this paper with inquiries for future research: What kinds of struggles do gender dysphoric people experience in different forms of meditation? Using Buddhist and other philosophical traditions, how might other scholars come to conceptualize dysphoria? What place does "sustained trauma" have in future conversations about meditation and experiences of gender dysphoric practitioners? Lastly, in further conceptualizing "sustained trauma," how might we account for the particular ways race, class, sexual trauma, and other modalities inform the longevity of traumatic remembrance, especially in how these experiences arise in the field of meditation?

Funding: This research received no external funding.

Conflicts of Interest: The author declares no conflict of interest.

\section{References}

Aitken, Madison, Doug VanderLaan, Lori Wasserman, Sonja Stojanovski, and Kenneth Zucker. 2016. Self-Harm and Suicidality in Children Referred for Gender Dysphoria. Journal of the American Academy of Child and Adolescent Psychiatry 55: 513-20. [CrossRef] [PubMed]

APA-American Psychological Association. 2020a. Distress; APA Dictionary of Psychology. Available online: https://dictionary.apa.org/distress (accessed on 15 September 2020).

APA-American Psychological Association. 2020b. Trauma; APA Dictionary of Psychology. Available online: https://dictionary.apa.org/trauma (accessed on 15 September 2020).

Astin, John. 1997. Stress reduction through mindfulness meditation. Effects on psychological symptomatology, sense of control, and spiritual experiences. Psychotherapy and Psychosomatics 66: 97-106. [CrossRef] [PubMed]

Bailey, Heidi Neufeld, Greg Moran, and David Pederson. 2007. Childhood maltreatment, complex trauma symptoms, and unresolved attachment in an at-risk sample of adolescent mothers. Attachment $\mathcal{E}$ Human Development 9: 139-61.

Beauchemin, James, Tiffany Hutchins, and Fiona Patterson. 2008. Mindfulness Meditation May Lessen Anxiety, Promote Social Skills, and Improve Academic Performance among Adolescents with Learning Disabilities. Journal of Evidence-Based Integrative Medicine 13: 34-45. [CrossRef]

Bockting, Walter. 2014. The Impact of Stigma on Transgender Identity Development and Mental Health. In Focus on Sexuality Research. Gender Dysphoria and Disorders of Sex Development: Progress in Care and Knowledge. Berlin: Springer Science + Business Media.

Bouman, Walter, Laurence Claes, Nicky Brewin, John Crawford, Nessa Millet, Fernando Fernandez-Aranda, and Jon Arcelus. 2017. Transgender and anxiety: A comparative study between transgender people and the general population. International Journal of Transgenderism 18: 16-26. [CrossRef]

Brach, Tara. 2003. Radical Acceptance: Embracing Your Life with the Heart of a Buddha. New York: Bantam Books.

Britton, Willoughby. 2019. Can mindfulness be too much of a good thing? The value of a middle way. Current Opinion in Psychology 28: 159-65. [CrossRef] [PubMed]

Chödrön, Pema. 2006. Practicing Peace in Times of War. Boston: Shambhala Publications.

Clark, Terryann, Mathijs Lucassen, Pat Bullen, Simon Denny, Theresa Fleming, Elizabeth Robinson, and Fiona Rossen. 2014. The health and well-being of transgender high school students: Results from the New Zealand adolescent health survey (Youth'12). Journal of Adolescent Health 55: 93-99. [CrossRef] [PubMed]

Connolly, Maureen, Marcus Zervos, Charles Barone II, Christine Johnson, and Christine L.M. Joseph. 2016. The Mental Health of Transgender Youth: Advances in Understanding. Journal of Adolescent Health 59: 489-95. [CrossRef] [PubMed]

Corless, Roger. 2007. Towards a queer dharmology of sex. Culture and Religion 5: 229-43. [CrossRef] 
Fetty, Danielle. 2016. Is There Justice for Sexual Trauma? A Structural Model to Examine Factors Influencing Posttraumatic Growth and Distress. Ph.D. dissertation, Southern Illinois University Carbondale, Carbondale, IL, USA.

Follette, Victoria, Kathleen Palm, and Adria Pearson. 2006. Mindfulness and trauma: Implications for treatment. Journal of Rational-Emotive and Cognitive-Behavior Therapy 24: 45-61. [CrossRef]

Ford, Julian. 2017. Complex Trauma and Complex Posttraumatic Stress Disorder. In APA Handbook of Trauma Psychology: Vol. 1. Foundations in Knowledge. Washington, DC: American Psychological Association.

Giovanardi, Guido, Roberto Vitelli, Carola Maggiora Vergano, Alexandro Fortunato, Luca Chianura, Vittorio Lingiardi, and Anna Maria Speranza. 2018. Attachment Patterns and Complex Trauma in a Sample of Adults Diagnosed with Gender Dysphoria. Frontiers in Psychology 9: 1-13. [CrossRef] [PubMed]

Gleig, Ann. 2012. Queering Buddhism or Buddhist De- Queering? Reflecting on Differences amongst Western LGBTQI Buddhists and the Limits of Liberal Convert Buddhism. Theology and Sexuality 18: 198-214. [CrossRef]

Gleig, Ann. 2014. Dharma Diversity and Deep Inclusivity at the East Bay Meditation Center: From Buddhist Modernism to Buddhist Post-Modernism? Contemporary Buddhism 15: 312-31. [CrossRef]

Hu, Hsiao-Lan. 2017. Buddhism and Sexual Orientation. In The Oxford Handbook of Contemporary Buddhism. Oxford: Oxford University Press.

Lev, Arlene. 2005. Disordering Gender Identity: Gender Identity Disorder in the DSM-IV-TR. Journal of Psychology and Human Sexuality 17: 35-70. [CrossRef]

Lindahl, Jared. 2017. Somatic Energies and Emotional Traumas: A Qualitative Study of Practice-Related Challenges Reported by Vajrayana Buddhists. Religions 8: 153. [CrossRef]

Lindahl, Jared, Nathan Fisher, David Cooper, Rochelle Rosen, and Willoughby Britton. 2017. The varieties of contemplative experience: A mixed-methods study of meditation-related challenges in Western Buddhists. PLoS ONE 12: e0176239. [CrossRef] [PubMed]

Mayo Clinic Staff. 2019. Gender Dysphoria; Mayo Clinic. Available online: https://www.mayoclinic.org/diseasesconditions/gender-dysphoria/symptoms-causes/syc-20475255 (accessed on 15 September 2020).

Ramel, Wiveka, Philippe Goldin, Paula Carmona, and John McQuaid. 2004. The Effects of Mindfulness Meditation on Cognitive Processes and Affect in Patients with Past Depression. Cognitive Therapy and Research 28: 433-55. [CrossRef]

Scherer, Bee. 2020. Queering Buddhism. In Oxford Research Encyclopedia of Religion. Oxford: Oxford University Press. Suzuki, Shunryū. 1975. Zen Mind, Beginner's Mind. New York: Weatherhill.

Treleaven, David. 2018. Trauma-Sensitive Mindfulness: Practices for Safe and Transformative Healing. New York: W.W. Norton \& Company.

Ueda, Shizuteru, James Heisig, and Frederick Greiner. 1982. Emptiness and Fullness: Śūnyatā in Mahāyāna Buddhism. The Eastern Buddhist 15: 9-37.

Publisher's Note: MDPI stays neutral with regard to jurisdictional claims in published maps and institutional affiliations.

(C) 2020 by the author. Licensee MDPI, Basel, Switzerland. This article is an open access article distributed under the terms and conditions of the Creative Commons Attribution (CC BY) license (http://creativecommons.org/licenses/by/4.0/). 